DOI: 10.17707/AgricultForest.64.3.04

\author{
Yannawut UTTARUK, Teerawong LAOSUWAN ${ }^{1}$
}

\title{
COMMUNITY FOREST FOR GLOBAL WARMING MITIGATION: THE TECHNIQUE FOR ESTIMATION OF BIOMASS AND ABOVE GROUND CARBON STORAGE USING REMOTE SENSING METHOD
}

\section{SUMMARY}

This study aims to present remote sensing methods for the analysis and comparison of different physical parameters for estimation of biomass and above ground carbon storage in the study areas of the pilot project for the chosen community forest in Maha Sarakham Province, Thailand. The implementation method was divided into four steps as follows. (1) Analysis of Landsat-8 satellite data with six physical parameters in the study (NDVI, TNDVI, GVI, IR-R, IR/R, and MSAVI2) and analyzing the results obtained to find out Fraction Cover (FC) value, (2) Field surveying by creating survey plots, measuring the circumference and the height of trees, and bringing the results to calculate above ground biomass with allometric equations (3) Creating correlation equations from the analysis results from Step 1 and Step 2, then applying the correlation equations obtained to calculate Carbon Dioxide $\left(\mathrm{CO}_{2}\right)$ storage by using remote sensing methods, and (4) Comparing optimal methods from six physical parameters. The analysis results of six physical parameters were found that GVI was the most appropriate method, the correlation equation $\mathrm{y}=1.8312 \mathrm{e}^{0.0168 \mathrm{x}}$, and the coefficient of determination $\left(\mathrm{R}^{2}\right)=0.8107$. And the $\mathrm{CO}_{2}$ storage capacity of the community forests in the study areas in Maha Sarakham Province was equal to 106.04 tonCO ${ }_{2}$ e from the total area of 61.24 ha.

Keywords: Community Forest, Remote Sensing, Biomass, Above Ground Carbon Storage

\section{INTRODUCTION}

Environmental issues have gained widespread attentions from all regions of the world, especially the problem of global warming (Ghent et al., 2011; Jones et al., 2012; Gomasathit et al., 2015; Hawkins et al., 2017). The main cause of this problem is greenhouse gases that store some of solar heat in the earth and do not reflect into the atmosphere (Lee et al., 2009). At any rate, Intergovernmental Panel on Climate Change (IPCC) of The United Nations had concluded that, from the observation of the average global temperature increase in the mid- $20^{\text {th }}$ century, it is quite evident that the increase in greenhouse gas emissions is caused

\footnotetext{
${ }^{1}$ Yannawut Uttaruk, Department of Biology, Faculty of Science, Mahasarakham University, Khamrieng, Katarawichai, Mahasarakham, THAILAND, Teerawong Laosuwan (corresponding author: teerawong@msu.ac.th), Department of Physics, Faculty of Science, Mahasarakham University, Khamrieng, Katarawichai, Mahasarakham, THAILAND.

Notes: The authors declare that they have no conflicts of interest. Authorship Form signed online.
} 
by human activities and results in the phenomenon of greenhouse gases (Goody and Yung, 1989). The solution for this problem is to reduce greenhouse gas emissions. Ones of the most acceptable methods are reforestation and forest management for conservation purposes due to verdant forests can effectively absorb $\mathrm{CO}_{2}$, which is one of greenhouse gases (Vicharnakorn et al., 2014). Forests are directly related to the amount of $\mathrm{CO}_{2}$ that is a major greenhouse gas. In other words, forests play a role as a source and a sink. It depends on the land use change and ecological characteristics of each forest. In the growth of trees, there is a process of photosynthesis or $\mathrm{CO}_{2}$ absorption in the forest which changes $\mathrm{CO}_{2}$ into biomass above ground (stem, branches and leaves) and below ground (roots) (Ogawa et al., 1965). In addition, forests also play an important role in $\mathrm{CO}_{2}$ cycle on the earth's surface. In each year, forests will absorb $\mathrm{CO}_{2}$ approximately at 2.6 billion tones, while deforestation or land use changes generate approximately 1.6 billion tons of $\mathrm{CO}_{2}$ or equivalent to 5.9 billion tons of $\mathrm{CO}_{2}$ (IPCC, 2006).

Previously, the amount of $\mathrm{CO}_{2}$ storage in the forest areas surveyed by people took quite a long time, especially in large areas of forests (Senpaseuth et al.,2009; Liaghat and Balasundram, 2010). Therefore, remote sensing technology had been applied to help evaluate $\mathrm{CO}_{2}$ storage (Gibert et al., 2008; Anindya and Yadavand, 2012; Robinson et al., 2013; Vagen and Winowiecki, 2013; Han et al., ;Laosuwan and Uttaruk, 2016).Currently, the study of remote sensing technology is on the progress so that the study of phenomena on the earth's surface can be implemented easier and the data obtained are quite real-time. As a result, there are many researchers applied the information from remote sensing technology widespread due to it is suitable in many aspects, namely wide range of data surveying, spatial resolution, spectral resolution, and multi temporal resolution with appropriate costs (Jiao et al.,2016; Yu et al.,2017).At any rate, the researches related to estimation of $\mathrm{CO}_{2}$ storage in community forests are hardly found in Thailand, especially the issue of community forests in Northeastern Thailand. For this reason, this study aims to present a technique for the analysis and comparison of different physical parameters for estimation of biomass and above ground $\mathrm{CO}_{2}$ storage in community forests in Maha Sarakham Province by using remote sensing methods.

\section{MATERIAL AND METHODS \\ Study areas and data collection}

- Study areas: Community forests (Figure 1) in Maha Sarakham Province in Northeastern Thailand were chosen to be pilot areas in this study including (1) the community forest in Nondaeng Sub-district, Borabue District, (2) the community forest in Nong Ruea Sub-district, Wapi Pathum District, (3) the community forest in Na Kha Sub-district, Wapi Pathum District, and (4) the community forest in Khwao Rai Sub-district, Kosum Phisai District. All these community forests have a total area of 61.24 ha. 


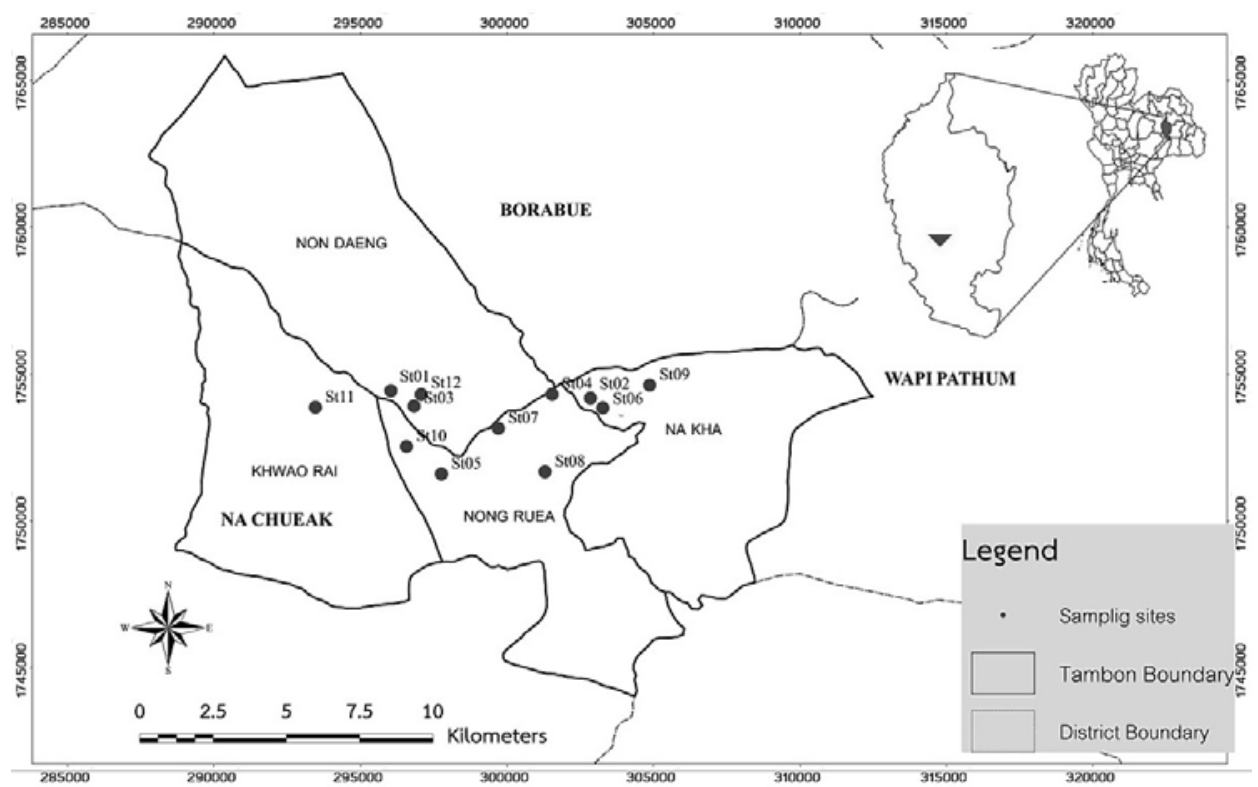

Figure 1. Community forests and 12 plots in order to be samples of the study areas

- Data collection: This study used the data from Landsat-8 satellite, path 127 and low 49 by recording the data on 29 November 2017.

\section{Implementation methods}

The implementation methods were divided into 4 main steps as follows.

\section{Analysis of Landsat-8 satellite data}

- Preparing data before analysis: Electromagnetic waves that travel from the sun to the top of the atmosphere (ToA) will depend on the distance between the earth and the sun including the angle of incidence. Some parts of electromagnetic waves will cause some phenomena, such as scattering, by air molecules, clouds and dust. And some will partially have absorbed by ozone, gases, dust and clouds. The rest will reflect objects on the earth's surface back into the satellite data recorders. This phenomenon may result in erroneous recording of satellite data. To reduce the effect of electromagnetic waves from the mentioned phenomena, this research aims to adjust the top of atmosphere (ToA) for data accuracy in two steps: (1) Converting digital number to radiance and (2) Converting radiance to ToA reflectance (Laosuwan and Uttaruk, 2014).

- Satellite data analysis: Analyzing Landsat-8 satellite data with six physical parameters including Normalized Difference Vegetation Index (NDVI), Transformed Normalized Difference Vegetation Index (TNDVI), Green Vegetation Index (GVI) (Gandia et al., 2004), Difference Vegetation Index (DVI) or IR-R (Tucker, 1979; Agapiou et al., 2012), Simple Ratio (SR) or IR/R (Jordan, 1969), and Second Modified Soil Adjusted Vegetation Index (MSAVI2) (Qi et al., 1994) (Equation 1 to Equation 6) and bringing the results from these 
six physical parameters to find out FC value (Uttaruk and Laosuwan, 2016) as shown in Equation 7.

$$
N D V I=\frac{N I R-R E D}{N I R+R E D}
$$

Where;

$N I R=$ Near infrared band of Landsat 8 OLI

$R=$ Red band of Landsat 8 OLI

$$
T N D V I=((N I R-R E D) /(N I R+R E D)+0.5)
$$

Where;

$N I R=$ Near infrared band of Landsat 8 OLI

$R=$ Red band of Landsat 8 OLI

$$
D V I=N I R-R E D
$$

Where;

$$
\begin{aligned}
& N I R=\text { Near Infrared Band } \\
& R E D=\text { Red band }
\end{aligned}
$$

$$
S R=N I R / R E D
$$

Where;

NIR $=$ Near Infrared Band

$R E D=$ Red band

$$
\begin{gathered}
G V I=(0.2848 \times B 1)-(0.2435 \times B 2)-(0.5436 \times B 3)+ \\
(0.7243 \times B 4)+(0.0840 \times B 5)-(0.1800 \times B 7)
\end{gathered}
$$

Where;

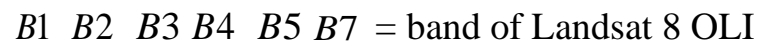

$$
M S A V I 2=\frac{(2 N I R+1)-\sqrt{(2 N I R+1)^{2}-8(N I R-R E D)}}{2}
$$

Where:

MSAVI $2=$ Vegetation Index

$N I R=$ Near Infrared Band Reflectance

$R E D=$ Red Band Reflectance

$$
F C=\frac{\left(V I-V I_{\text {open }}\right)}{\left(V I_{\text {canopy }}-V I_{\text {open }}\right)} \times 100
$$

Where;

$F C=$ Tree canopy fractional cover

$V I=$ Vegetation index

$V I_{\text {open }}=$ Vegetation index of open areas

$V I_{\text {canopy }}=$ Vegetation index of tree canopy 


\section{Field Survey}

- Measurement of trees: The sample plots $20 \mathrm{~m}$ x $20 \mathrm{~m}$ were arranged in the study areas in a total of 12 plots in order to be samples of the study areas of 61.24 ha. Then, the data of types and the number of large trees with diameters at Breast Height (DBH) of $4.5 \mathrm{~cm}$ and above, and the height of trees were measured and collected by using Clinometer. All the data collected in this study will be recorded in a record form for further analysis.

- Above ground biomass calculation: The field survey data were used to calculate quantitative ecological characteristics based on the height and diameter of trees and represented in the allometric equation (Ogawa et al., 1965). For the amount of above ground biomass dry dipterocarp forest was calculated in the stem, branches and leaves. The amount of biomass of above ground trees obtained was calculated to estimate the amount of $\mathrm{CO}_{2}$ (Ogawa et al., 1965).

\section{Creating statistical correlation equations}

This step created correlation equations from the analysis results of Step 1 and Step 2. Then, the correlation equations obtained were calculated to estimate the amount of $\mathrm{CO}_{2}$ storage in the study areas.

\section{Comparison of appropriate implementation methods}

This step compared the analysis results of the data from six physical parameters including NDVI, TNDVI, GVI, IR-R, IR/R, and MSAVI2. Then, the most appropriate method will be chosen to calculate the amount of $\mathrm{CO}_{2}$ storage in the study areas.

\section{Result}

\section{RESULTS AND DISCUSSION}

\section{- Analysis of Landsat-8 satellite data}

Analyzing Landsat-8 satellite data with six physical parameters including NDVI, TNDVI, GVI, IR-R, IR/R, and MSAVI2 and bringing the results from these six physical parameters to find out FC value as shown in Figure 2. From the Figure 2, display that the location of the brightest area shows the area covered by the vegetation. On the other hand, gray to black areas have low vegetation cover and no vegetation cover respectively.

\section{-Field survey results}

From the sample plots of the study areas in a total of 61.24 ha and the tree measurements as mentioned above, the researchers brought the results to analyze the amount of biomass by allometric equations and converted biomass to carbon. The results of the calculation are shown in Table 1.

\section{-Creating statistical correlation equations and data analysis}

Creating statistical correlation equations between Landsat-8 satellite data and field data was to find out the correlation between $\mathrm{FC}$ value analyzed by six physical parameters (NDVI, TNDVI, GVI, IR-R, IR/R, and MSAVI2) and the amount of biomass analyzed from the field data. Then, the correlation equations obtained were calculated to estimate the amount of $\mathrm{CO}_{2}$ storage. The results of 
creating statistical correlation equations are shown in Figure 3 and Landsat-8 satellite data analysis can be displayed as shown in Figure 4.

Table 1. Field survey results

\begin{tabular}{ccc}
\hline Plot name & Area (ha) & Carbon value tons/ha \\
\hline 1 & 05.44 & 00.86 \\
2 & 04.32 & 10.34 \\
3 & 06.40 & 01.76 \\
4 & 08.16 & 02.88 \\
5 & 04.00 & 00.61 \\
6 & 03.20 & 01.16 \\
7 & 11.20 & 01.84 \\
8 & 06.72 & 01.62 \\
9 & 02.56 & 04.43 \\
10 & 02.40 & 02.02 \\
11 & 03.20 & 00.42 \\
12 & 03.64 & 00.68 \\
\hline Total & 61.24 & 28.63 \\
\hline
\end{tabular}

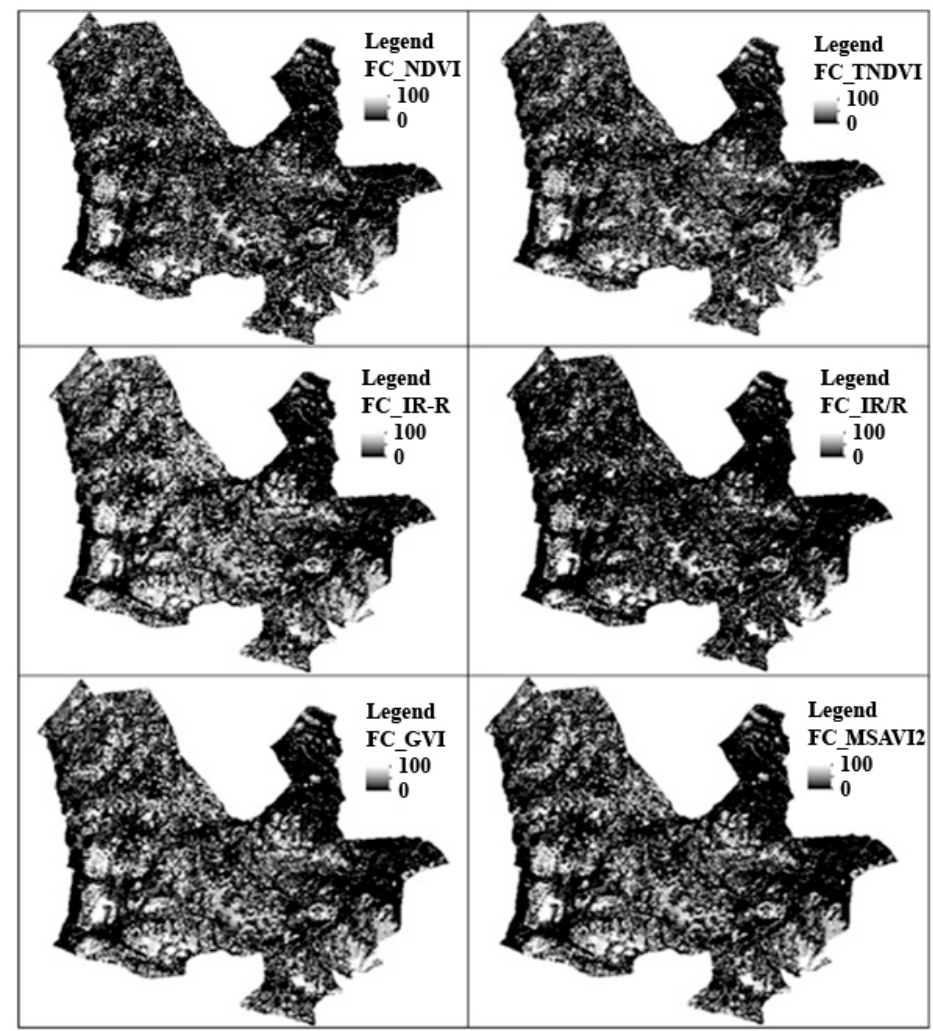

Figure 2. Analyzing Landsat-8 satellite data with six physical parameters 


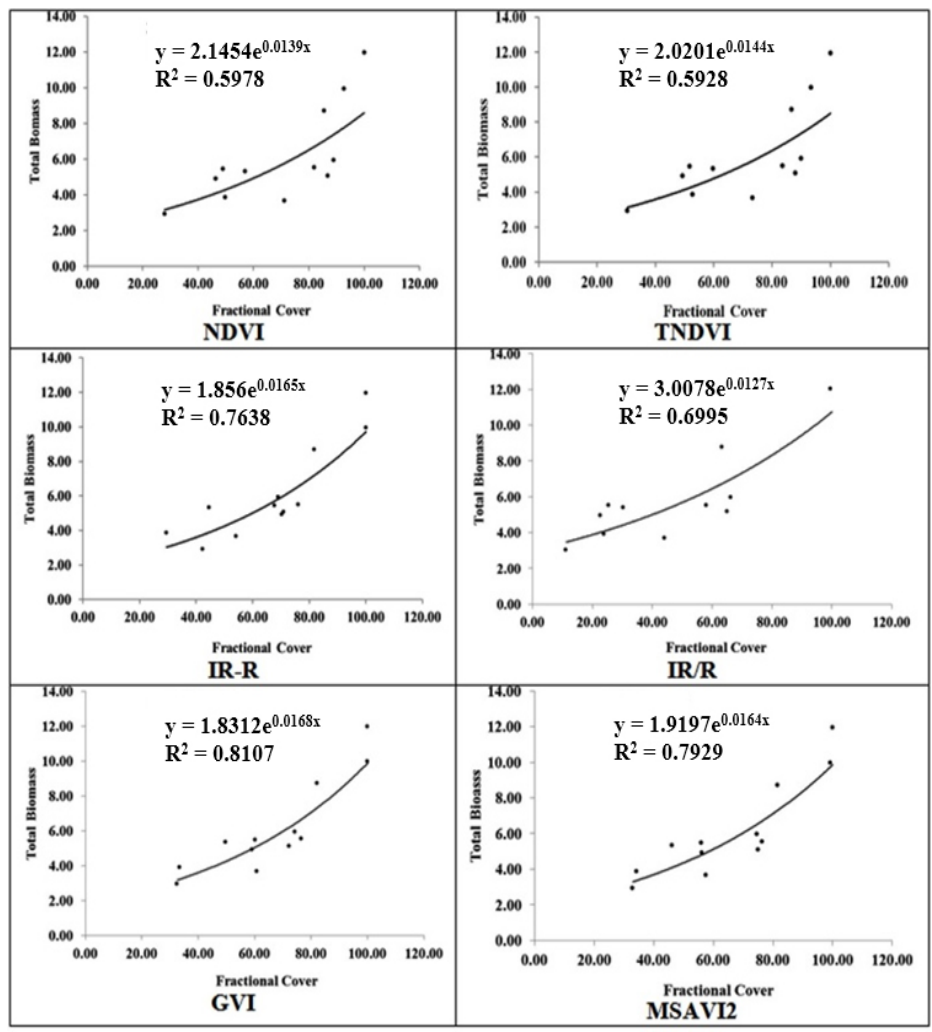

Figure 3. Relationship of the statistical data

\section{-Comparison results of the appropriate methods}

The comparison results of the six physical parameters in this study (NDVI, TNDVI, GVI, IR-R, IR/R, and MSAVI2) can be explained as follows: 1) The physical parameter NDVI obtained the correlation equation $\mathrm{y}=2.1454 \mathrm{e}^{0.0139 \mathrm{x}}$ and coefficient of determination $\left(\mathrm{R}^{2}\right)=0.5978$. As a result, the amount of biomass can be estimated at $25.43 \mathrm{tC} /$ ha and the $\mathrm{CO}_{2}$ storage in the study areas can be estimated at 93.24 tonCO $\mathrm{C}_{2}$ e. 2) The physical parameter TNDVI obtained the correlation equation $\mathrm{y}=2.0201 \mathrm{e}^{0.0144 \mathrm{x}}$ and coefficient of determination $\left(\mathrm{R}^{2}\right)=$ 0.5928 . As a result, the amount of biomass can be estimated at $25.95 \mathrm{tC} / \mathrm{ha}$ and the $\mathrm{CO}_{2}$ storage in the study areas can be estimated at 95.15 tonCO${ }_{2} \mathrm{e} .3$ ) The physical parameter GVI obtained the correlation equation $\mathrm{y}=1.8312 \mathrm{e}^{0.0168 \mathrm{x}}$ and coefficient of determination $\left(\mathrm{R}^{2}\right)=0.8107$. As a result, the amount of biomass can be estimated at $28.91 \mathrm{tC} /$ ha and the $\mathrm{CO}_{2}$ storage in the study areas can be estimated at 106.04 tonCO $\mathrm{C}_{2} \mathrm{e}$. 4) The physical parameter IR-R obtained the correlation equation $\mathrm{y}=1.856 \mathrm{e}^{0.0165 \mathrm{x}}$ and coefficient of determination $\left(\mathrm{R}^{2}\right)=$ 0.7638 . As a result, the amount of biomass can be estimated at $28.33 \mathrm{tC} / \mathrm{ha}$ and the $\mathrm{CO}_{2}$ storage in the study areas can be estimated at 103.87 tonCO $\mathrm{C}_{2} \mathrm{e}$. 5) The physical parameter IR/R obtained the correlation equation $\mathrm{y}=3.0078 \mathrm{e}^{0.0127 \mathrm{x}}$ and coefficient of determination $\left(\mathrm{R}^{2}\right)=0.6995$. As a result, the amount of biomass 
can be estimated at $26.26 \mathrm{tC} / \mathrm{ha}$ and the $\mathrm{CO}_{2}$ storage in the study areas can be estimated at 96.32 tonCO ${ }_{2}$ e. 6) The physical parameter MSAVI2 obtained the correlation equation $\mathrm{y}=1.9197 \mathrm{e}^{0.0164 \mathrm{x}}$ and coefficient of determination $\left(\mathrm{R}^{2}\right)=$ 0.7929. As a result, the amount of biomass can be estimated at $28.01 \mathrm{tC} / \mathrm{ha}$ and the $\mathrm{CO}_{2}$ storage in the study areas can be estimated at 102.70 tonCO $\mathrm{C}_{2} \mathrm{e}$.

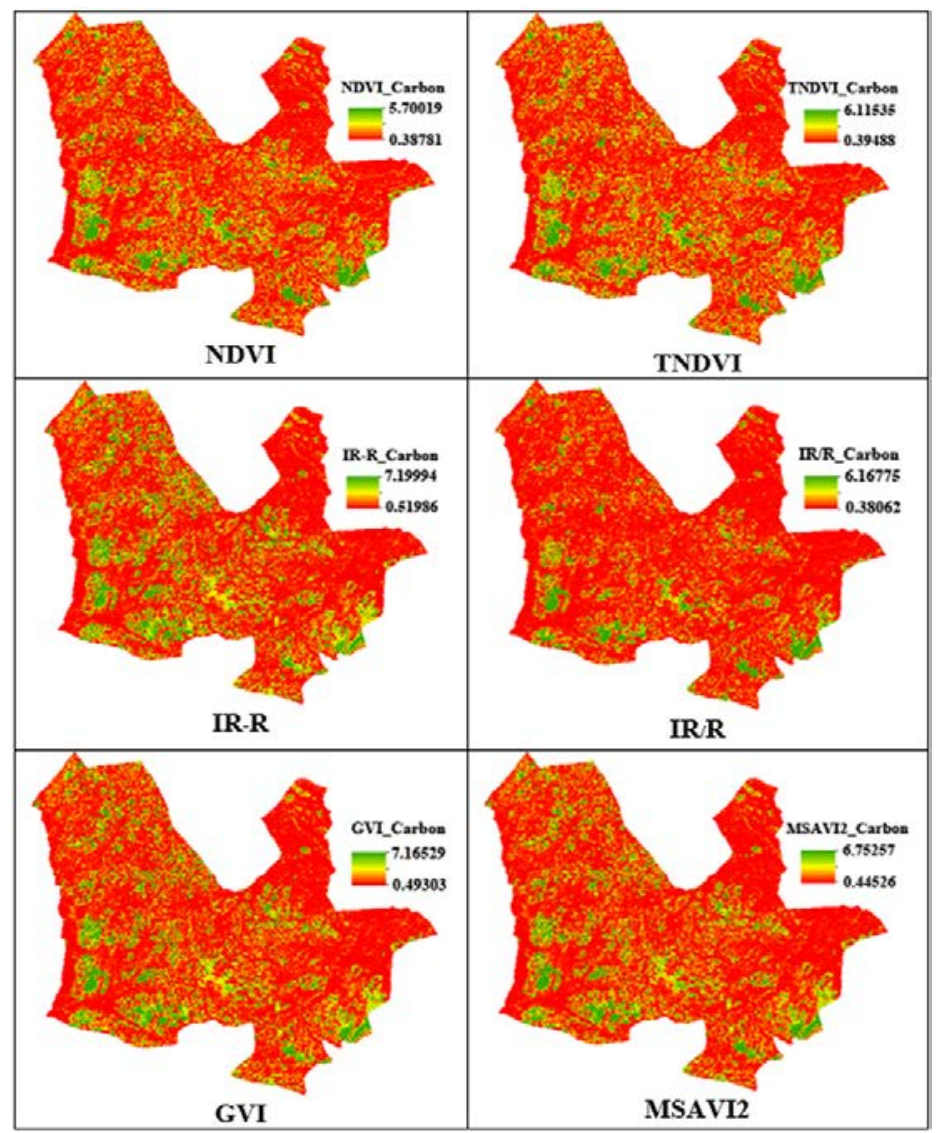

Figure 4. The spatial data after substituting value

For the analysis to find the appropriateness of the assessment of biomass and carbon storage above the community forest, considering from coefficient of determination $\mathrm{R}^{2}$ received from the relationship between FC analyzed from the six patterns of physical parameters and the volume of biomass in the field, coefficient of determination $\mathrm{R}^{2}$ from GVI physical parameter has the highest value and therefore it is the most appropriate method. GVI will lead to $\mathrm{y}=$ $1.8312 \mathrm{e}^{0.0168 \mathrm{x}}$ with coefficient of determination $\mathrm{R}^{2}=0.8107$. It can calculate the volume of $\mathrm{CO}_{2}$ storage at 106.04 tonCO $\mathrm{C}_{2} \mathrm{e}$. Regarding tCO2e/ha, it was found that the volume of $\mathrm{CO}_{2}=1.73 \mathrm{tCO} 2 \mathrm{e} / \mathrm{ha}$. As compared the result with the research of dry dipterocarp forest in Thailand by Boonsang and Arunpraparat (2011), it was discovered that the volume of $\mathrm{CO}_{2}$ storage is 200.49 tCO2e/ha. 
Meanwhile, the work of Vicharnakhon et al., (2014) found that the volume of carbon storage is 82.70 tCO2e/ha and the work of Ounkerd et al (2015) is 391.42 tCO2e/ha. The three research articles studied the large single patch forest type which differs from this study, which means the type of this community forest is small forest patch surrounding with paddy field and another land use types (small scatter forest patch) that was counted as the common divisor. For this reason, the result of the volume of carbon storage, tCO2e/ha, is quiet low. Moreover, Paired Samples Test was applied to test the statistical significance between field data and data analyzed from the 6 physical parameters which found that the statistical significance is at $95 \%$.

\section{CONCLUSIONS}

The purpose of this study was to present the technique to analyze and compare the different physical parameters for the above ground assessment of biomass and carbon storage in a pilot study of the community forest in Maha Sarakham Province, using the data received from Landsat-8 satellite and six patterns of physical parameters including field study to create equation model of relationship before the assessment of biomass and carbon storage. According to the study of the above-ground assessment of biomass and carbon storage for the forest community in 12 studying fields, the forest community is classified as dry dipterocarp forest. As in the survey, 31 families of plants and 51 types were founds. The total number of trees is 692 and the average DBH is $8.54 \mathrm{~cm}$ while the average height is $7.10 \mathrm{~m}$. Considering the study, the assessment of biomass and carbon storage requires no field study in all areas which will reduce the expense of field study and also reduce the time of researching while the data will be up-to-date and respond the demand of data in the urgent time.

\section{ACKNOWLEDGEMENTS}

This research was financially supported by Mahasarakham University grant year 2018.

\section{REFERENCES}

Agapiou A., Hadjimitsis D.G., and Alexakis, D.D. 2012. Evaluation of Broadband and Narrowband Vegeta $\neg$ tion Indices for the Identification of Archaeological Crop Marks. Remote Sens., 4, 3892-3919.

Anindya, M.K., and Yadavand, N. 2012. Applying enhanced k-Nearest neighbor approach on satellite images for forest biomass estimation of Vellore district. Eng. Sci. Technol. Int. J., 2, 2250-3498.

Boonsang, S., Arunpraparat, W., 2011. Estimation of Above-Ground Carbon Sequestration of Forest Using Remote Sensing Techniques in Mae Tuen Wildlife Sanctuary, Tak Province. Thai Journal of Forestry, 30 (3), 14-23.

Gandia, S., Fernández, G., García, J. C., and Moreno, J. 2004. Retrieval of vegetation biophysical variables from CHRIS/PROBA data in the SPARC campaing. Proceedings of the 2nd CHRISProba Workshop ESAESRIN Frascati Italy, 28-30 April 2004, 40-48. 
Ghent, D., Kaduk, J., Remedios, J. and Balzter, H. 2011. Data assimilation into land surface models: the implications for climate feedbacks. International Journal of Remote Sensing, 32(3), 617-632.

Gibert, F., Flamant, P.H., Cuesta, J., Bruneau, D. 2008. Vertical 2-_m heterodyne differential absorption lidar measurements of mean $\mathrm{CO} 2$ mixing ratio in the troposphere. J. Atmos. Ocean. Technol., 25, 1477-1497.

Gomasathit, T., Laosuwan, T., Sangpradit, S., and Rotjanakusol, T. 2015. Assessment of Drought Risk Area in Thung Kula Rong Hai using Geo-graphic Information System and Analytical Hierar $\neg$ chy Process. International Journal of Geoinformat $\neg$ ics, 11 (2), 21-27.

Goody, R.M., and Yung, Y.L. 1989. Atmospheric Radiation: Theoretical Basis, Oxford, United States of America.

Han, G., Ma, X., Liang, A., Zhang, T., Zhao, Y., Zhang, M., Gong, W. 2017. Performance Evaluation for China's Planned CO2-IPDA. Remote Sens., 9, 768.

Hawkins, E., Ortega, P., Suckling, E., Schurer, A., Hegerl, G., Jones, P., Joshi, M., Osborn, T. J., Masson-Delmotte, V., Mignot, J., Thorne, P. and van Oldenborgh, G. J. 2017. Estimating changes in global temperature since the preindustrial period. Bulletin of the American Meteorological Society, 98 (9). 1841-1856.

Jiao, W., Zhang, L., Chang, Q., Fu, D., Cen, Y., and Q. Tong. 2016. Evaluating an Enhanced Vegetation Condition Index (VCI) Based on VIUPD for Drought Monitoring in the Continental United States. Remote Sens., 8(3), 2-21.

Jones, P.D., Lister, D.H., Osborn, T.J., Harpham, C., Salmon, M. and Morice, C.P. 2012. Hemispheric and large-scale land surface air temperature variations: an extensive revision and an update to 2010. Journal of Geophysical Research, 117, 1-29.

Jordan, C.F. 1969. Derivation of leaf area index from quality of light on the forest floor. Ecology, 50, 663-666.

IPCC. 2006. Guidelines for National Greenhouse Gas Inventories. http://www. ipccnggip.iges.or.jp/public/2006gl/index.html (accessed November 2017)

Laosuwan, T. and Uttaruk, P. 2014. Estimating Tree Biomass via Remote Sensing, MSAVI 2, and Fractional Cover Model. IETE Technical Review, 31(5), 362-368.

Laosuwan, T., and Uttaruk, Y. 2016. Estimating Above Ground Carbon Capture Using Remote Sensing Technology in Small Scale Agroforestry Areas. Agriculture \& Forestry, 62 (2), 253-262.

Lee, K. H., Li, Z., Kim, Y. J., and Kokhanovsky, A. A. 2009. Atmospheric aerosol monitoring from satellite observations: a history of three decades, in Atmospheric and Biological Environmental Monitoring, edited by: Kim, Y. J., Platt, U., Gu, M. B., and Iwahashi, H.,Springer, Berlin, 13-38.

Lemke, P., Ren, J., Alley, R. B., Allison, I., Carrasco, J., Flato, G., Fujii, Y., Kaser, G., Mote, P., Thomas, R. H. and Zhang, T. 2007. Observations: Changes in Snow, Ice and Frozen Ground., Title: Climate change 2007: the physical science basis; summary for policymakers, technical summary and frequently asked questions. Part of the Working Group I contribution to the Fourth Assessment Report of the Intergovernmental Panel on Climate Change.

Liaghat, S., and Balasundram, S.K. 2010. A review: The role of remote sensing in precision agriculture. American Journal of Agricultural and Biological Sciences, 5, 50-55.

Ogawa, H., Yoda, K., Ogino, K. and Kira, T. 1965. Comparative ecological studies on three main types of forest vegetation in Thailand II. Plant biomass. Natural and life in Southeast Asia, 4, 49-80. 
Ounkerd, K., Sunthornhao, P., Puangchit, L. 2015. Valuation of Carbon Stock in Trees at Khao Wong Community Forest, Chaiyaphum Province. Thai Journal of Forestry, 34 (1), 29-38.

Qi, J., Chehbouni, A., Huete, A.R., Kerr, Y.H. 1994. Modified Soil Adjusted Vegetation Index (MSAVI). Remote Sensing Environment, 48, 119-126.

Robinson, C., Saatchi, S., Neumann, M., Gillespipe, T. 2013. Impacts of spatial variability on aboveground biomass estimation from L-band Radar in a temperate forest. Remote Sens., 5, 1001-1023.

Senpaseuth, P., Navanugraha, C., and Pattanakiat, S. 2009. The Estimation of Carbon Storage in Dry Evergreen and Dry Dipterocarp Forests in Sang Khom District, Nong Khai Province, Thailand. Environment and Natural Resources Journal, 7(2), $1-11$.

Tucker, C.J. 1979. Red and photographic infrared linear combinations for monitoring vegetation.Remote Sens. Environ., 8, 127-150.

Uttaruk, Y., and Laosuwan, T. 2016. Remote Sensing Based Vegetation Indices for Estimating Above Ground Carbon Sequestration in Orchards. Agriculture \& Forestry, 62 (4), 193-201.

Vagen, T.G., and Winowiecki, L.A. 2013. Mapping of soil organic carbon stocks for spatially explicit assessments of climate change mitigation potential. Environ. Res. Lett., 8, 1748-1793.

Vicharnakorn, P., Shrestha, R.P., Nagai, M., Salam, A.P., Kiratiprayoon, S. 2014. Carbon Stock Assessment Using Remote Sensing and Forest Inventory Data in Savannakhet, Lao PDR. Remote Sensing, 6, 5452-5479.

Yu, J., Petros, M., Singh, U.N., Refaat, T.F., Reithmaier, K., Remus, R.G., Johnson, W. 2017. An Airborne 2- $\mu \mathrm{m}$ Double-Pulsed Direct-Detection Lidar Instrument for Atmospheric CO2 Column Measurements. J. Atmos. Ocean. Technol., 34, 385400. 